\title{
Role of microRNAs in primary central nervous system lymphomas
}

\author{
Xin Yu*, Zheng Li†, Jianxiong Shen†, Matthew T.V. Chanł and William Ka Kei Wuł§ \\ *Department of Dermatology, Peking Union Medical College Hospital, Chinese Academy of Medical Sciences \& Peking Union Medical College, \\ Beijing 100042, China, †Department of Orthopedics Surgery, Peking Union Medical College Hospital, Chinese Academy of Medical Sciences and \\ Peking Union Medical College, Beijing 100042, China, \$Department of Anaesthesia and Intensive Care, The Chinese University of Hong Kong, \\ Hong Kong 999077, China and §State Key Laboratory of Digestive Disease, LKS Institute of Health Sciences, The Chinese University of Hong \\ Kong, Hong Kong 999077, China
}

Received 19 September 2015; revision accepted 16 November 2015

\begin{abstract}
Primary central nervous system lymphomas (PCNSL) are extranodal non-Hodgkin lymphomas arising exclusively inside the CNS, and account for about $3 \%$ of primary intracranial tumours. This tumour lacks systemic manifestations and prognosis of patients with PCNSL remains poor despite recent advancement of chemoradiotherapy. MicroRNAs are small non-coding RNAs that post-transcriptionally downregulate gene expression by binding to target mRNAs, inducing their degradation or translational repression. MicroRNAs play significant roles in almost all malignancy-related biological processes, including cell proliferation, differentiation, apoptosis and metabolism. Many deregulated miRNAs has been identified in PCNSL but their biological significance remains to be fully elucidated. In this review, we summarize current evidence regarding the pathogenic role of PCNSLassociated microRNAs and their potential applications for diagnosis and prognostication of this deadly disease.
\end{abstract}

\section{Introduction}

Primary central nervous system lymphomas (PCNSL) are an aggressive, extra nodal form of non-Hodgkin lymphomas (NHL) that arise exclusively in the CNS, including the brain, leptomeninges, spinal cord and eyes, in the absence of systemic dissemination. PCNSL

Correspondence: J. Shen, Department of Orthopedics Surgery, Peking Union Medical College Hospital, Chinese Academy of Medical Sciences and Peking Union Medical College, Beijing 100042, China. Tel.: +86010 69152812; Fax: +86010 69152812;

E-mail: shenjianxiong@medmail.com.cn

$\mathrm{Xin} \mathrm{Yu}$ and $\mathrm{Zheng} \mathrm{Li}$ contributed equally to this work. accounts for $2-4 \%$ of primary intracranial tumours and $1 \%$ of all lymphomas (1).The incidence of PCNSL increases with age in immunocompetent populations. Immunodeficiency as a result of human immunodeficiency virus (HIV) infection or immunosuppressive medications for organ transplantation also increases the risk but this form of PCNSL has a different pathogenesis (e.g. association with Epstein-Barr virus (EBV) infection) with distinct therapeutic implications (1-3). In contrast to most primary malignant brain tumours, PCNSL can be curable by aggressive radio-chemotherapeutic approaches, such as high-dose methotrexate followed by whole-brain irradiation (4-6). However, delayed diagnosis and treatment is a common cause of death in PCNSL patients (7) in which early diagnosis is significant for improving survival and prognosis (8). Despite the recent advancement of imaging techniques, the diagnosis of PCNSL is still a clinical challenge (9). Stereotactic needle biopsy is currently the standard diagnostic method for patients with suspected PCNSL $(6,10,11)$. Therefore, identification of novel non-invasive method is required for improving the accuracy and shortening the delay of PCNSL diagnosis.

\section{Molecular pathogenesis and cellular origin of PCNSL}

About $90 \%$ of PCNSL are classified as diffuse large Bcell lymphomas (DLBCL). The cellular origin of PCNSL-DLCBL remains obscure but recent gene expression profiling studies suggests that it could originate from germinal centre $\mathrm{B}$ cells that are destined to become IgM-expressing memory B cells (12). The recent discovery of functional lymphatic vessels lining the dural sinuses that are connected to the deep cervical lymph nodes may also shed new light on the origin of malignant lymphocytes in the CNS (13). Mechanistically, blockade of B-cell differentiation due to PRDMI 
mutation, translocation-mediated overexpression of BCL6, activation of proto-oncogenes (e.g. PIM1, PAX5, RhoH/TTF, MYC) due to somatic hypermutation, and DNA hypermethylation of tumour suppressors (e.g. $D A P K, C D K N 2 A, M G M T$ ) have been proposed to play key roles in the pathogenesis of PCNSL (12). The advent of high throughput platforms, such as array-comparative genomic hybridization and whole exome sequencing, also revealed additional genomic features, including loss of TNFAIP3, PRDM1, GNA13, TMEM30A, TBL1XR1, B2M, CD58, NPFFR2, C4orf7, OSMR, EMCN, TPO, FNDC1, COL12A1 and MSC, and activating mutations of MYD88, CD79B, CARD11, $B R A F 3(14,15)$. In general, several signalling pathways, such as nuclear factor- $\kappa \mathrm{B}(\mathrm{NF}-\kappa \mathrm{B})$, Janus kinase-signal transducers and activators of transcription (JAK-STAT) and adhesion-related pathways, may be involved $(14,15)$. It is noteworthy that the molecular features, clinical behaviours and prognosis of PCNSL and peripheral DLBCL could differ considerably $(12,16)$. For instance, the mutation load of PCNSL is 2- to 5-fold higher than that of its peripheral counterpart (17). The former also harbours some specific genomic features, including recurrent biallelic losses of TOX (a regulator of T-cell development) and $P R K C D$ (protein kinase $\mathrm{C}$ delta) and chromosomal breakpoints in DLGAP1 (discs large-associated protein 1) (15). In general, the prognosis of PCNSL is worse than that of peripheral DLBCL (16).

MicroRNAs (miRNAs) are small (18-24 nucleotides in length) non-coding RNAs that post-transcriptionally downregulate gene expression by binding to target mRNA, triggering their degradation or translational repression $(18,19)$. miRNAs play significant roles in critical biological processes, including cell proliferation, differentiation, metabolism, apoptosis and tumourigenesis (20-25). In particular, deregulated expression of miRNAs is frequently observed in human cancers $(26,27)$. miRNAs can also function as tumour suppressors or oncogenes through their extensive crosstalk with intracellular signalling network $(28,29)$. Moreover, miRNA expression signatures have diagnostic, prognostic and therapeutic implications in some cancers (30-32).

\section{Differentially expressed miRNAs in PCNSL as compared with DLBCL}

Three studies have been published so far to compare miRNA expression of PCNSL with that of peripheral DLBCL. Using quantitative reverse transcription-PCR, Fischer et al. demonstrated that 18 miRNAs were differentially expressed in PCNSL compared with nodal DLBCL (33). Among them, the expression of 13 and 5
miRNAs was significantly upregulated and downregulated, respectively, in PCNSL compared with nodal DLBCL. In addition, miRNAs upregulated in PCNSL were implicated in various molecular functions. For example, miR-17-5p, miR-20a and miR-9 were associated with the Myc pathway, miR-9 and miR-30b/c with blocking of terminal B-cell differentiation, and miR-155 with upregulation by inflammatory cytokines. Furthermore, miRNAs downregulated in PCNSL were potential tumour-suppressor miRNAs. In conclusion, PCNSL showed a distinct miRNA expression compared with nodal DLBCL (33). In another study, Zheng et al. using miRNA hybridization demonstrated that expressions of 28 (e.g. miR-122, miR-513b, miR-552) and 33 (e.g. miR-363, miR-196a, miR-192) miRNAs/segments increased and decreased by more than 10-fold in PCNSL compared with that of non-germinal centre DLBCL (34). As compared with germinal centre DLBCL, the number of $>10$-fold upregulated and downregulated miRNAs/segments were 11 (e.g. miR-513b, miR-802, miR-512-3p) and 13 (e.g. miR-135a, miR592, miR-582-5p) respectively (34). Robertus et al. compared the miRNA expression profile in DLBCL from different primary sites (35). miR-17-5p expression levels were significantly higher in PCNSL than in testicular and nodal DLBCL. In addition, miR-127 was significantly downregulated in PCNSL and nodal DLBCL compared with the testicular type (35). Therefore, expressions of miRNAs are different in different primary sites of DLBCL. Differentially expressed miRNAs between PCNSL and peripheral DLBCL were shown in Table 1.

\section{Deregulated miRNAs and their putative functions in PCNSL}

$\operatorname{miR}-21$

miR-21 was upregulated in various cancers, acting as a well-established oncogenic miRNA (36-39). Importantly, miR-21 has been shown to contribute to pre-Bcell lymphomagenesis in which inhibition of miR-21 led to regression of tumours via apoptosis and cell cycle arrest in a mouse model (40). miR-21 also played a significant role in the chemosensitivity of DLBCL cells (40). The confirmed targets of miR-21 in DLBCL include FOXO1 (a transcription factor), PDCD4 (a positive regulator of apoptosis) and PTEN (an inhibitor of oncogenic phosphoinositide 3-kinase/Akt pathway) $(40,41)$. The levels of serum miR-21 were significantly higher in PCNSL than in other brain tumours and normal controls (42). Whether miR-21 was actively secreted from PCNSL cells via the exosome pathway 
Table 1. miRNA differentially expressed between PCNSL and DLBCL

\begin{tabular}{|c|c|c|c|c|c|}
\hline & Method & Sample & Upregulated & Downregulated & Reference \\
\hline 1 & $\begin{array}{r}\text { Microarray } \\
\text { qRT-PCR }\end{array}$ & $\begin{array}{l}\text { PCNSL and } \\
\text { nodal DLBCL }\end{array}$ & $\begin{array}{l}\text { miR-9 } \\
\text { miR-20b } \\
\text { miR-155 } \\
\text { miR-340 } \\
\text { miR-17-5p } \\
\text { miR-148a } \\
\text { miR-30b } \\
\text { miR-27b } \\
\text { miR-26b } \\
\text { miR-146b } \\
\text { miR-20a } \\
\text { miR-30c } \\
\text { let-7 g } \\
\text { miR-199a } \\
\text { miR-214 } \\
\text { miR-432 } \\
\text { miR-193b } \\
\text { miR-145 }\end{array}$ & $\begin{array}{l}\text { miR-296 } \\
\text { miR-361 } \\
\text { miR-301 } \\
\text { miR-642 } \\
\text { miR-29c }\end{array}$ & 33 \\
\hline 2 & $\begin{array}{r}\text { Microarray } \\
\text { qRT-PCR }\end{array}$ & $\begin{array}{l}\text { PCNSL and GC } \\
\text { and non-GC-DLBCL }\end{array}$ & $\begin{array}{l}\text { Compared with NGC-DLBCL } \\
\text { miR-122 } \\
\text { miR-513b } \\
\text { miR-522 } \\
\text { miR-1973 } \\
\text { miR-875-5p } \\
\text { miR-513a-5p } \\
\text { Compared with GC-DLBCL } \\
\text { miR-513b } \\
\text { miR-802 } \\
\text { miR-512-3p }\end{array}$ & $\begin{array}{l}\text { Compared with NGC-DLBCL } \\
\text { miR-363 } \\
\text { miR-196a } \\
\text { miR-192 } \\
\text { miR-10b } \\
\text { miR-192 } \\
\text { miR-193b } \\
\text { miR-1 } \\
\text { miR-218 } \\
\text { miR-339-3p } \\
\text { miR-223 } \\
\text { miR-215 } \\
\text { miR-374a } \\
\text { miR-365 } \\
\text { miR-199a-5p } \\
\text { miR-497 } \\
\text { miR140-5p } \\
\text { miR-135a } \\
\text { miR-140-3p } \\
\text { miR-199b-5p } \\
\text { miR-199a/b-3p } \\
\text { miR-503 } \\
\text { miR-425 } \\
\text { miR-181c } \\
\text { miR-424 } \\
\text { miR-570 } \\
\text { miR-146a } \\
\text { miR-194 } \\
\text { miR-545 } \\
\text { miR-320a } \\
\text { miR-454 } \\
\text { Compared with GC-DLBCL } \\
\text { miR-135a } \\
\text { miR-592 } \\
\text { miR-582-5p } \\
\text { miR-582-3p } \\
\text { miR-199b-5p } \\
\text { miR-339-3p } \\
\text { miR-146a } \\
\text { miR-10b }\end{array}$ & 53 \\
\hline 3 & qRT-PCR & PCNSL and nodal/testicular DLBCL & $\operatorname{miR}-175 p$ & miR-127 (compared with testicular DLBCL) & 34 \\
\hline
\end{tabular}

GC, germinal centre; qRT-PCR, quantitative reverse transcription-PCR 
Table 2. Functional characterization of the deregulated miRNAs in PCNSL

\begin{tabular}{llll}
\hline Name & $\begin{array}{l}\text { Up- or } \\
\text { downregulation }\end{array}$ & Role & Reference \\
\hline miR-21 & Up & Oncogene & $(40,42)$ \\
MiR-17-5p & Up & Oncogene & $(35)$ \\
miR-127 & Down & Tumour suppressor & $(35)$ \\
miR-17-92 & Up & Oncogene & $(46)$ \\
miR-106a-363 & Up & Oncogene & $(46)$ \\
miR-106b-25 & Up & Oncogene & $(46)$ \\
miR-222 & Up & Oncogene & $(60)$ \\
miR-199a-5p/3p & Down & Tumour suppressor & $(50)$ \\
miR-143/145 & Down & Tumour suppressor & $(50)$ \\
miRNA-28 & Deletion & Unknown & $(51)$ \\
\hline
\end{tabular}

(43) or continuously released into the circulation through cell death remains unclear.

miR-17-92, miR-106a-363 and miR-106b-25 clusters in HIV-associated PCNSL

The risk for NHL is significantly elevated in population with HIV infection (44). Acquired immune deficiency syndrome (AIDS)-associated NHL includes several Bcell lymphomas, such as Burkitt's lymphoma, DLBCL, PCNSL, primary effusion lymphoma and plasmablastic lymphomas (45). Overexpression of miR-17-92, miR106a-363 and miR-106b-25 were observed in four AIDSNHL subtypes, including PCNSL (46). Mechanistically, selected miRNAs from these clusters (miR-17, miR-106a and miR-106b) inhibited p21 (a cyclin-dependent kinase inhibitor) in AIDS-DLBCL samples (46). For miR-17-92 cluster, its member miR-19 has been identified as a key oncogenic component in the genesis of B-cell lymphoma by targeting PTEN and activating Akt-mTOR (mammalian target of rapamycin) pathway (47).

miR-199a-5p/3p and miR-143/145 in primary CNS posttransplant lymphoproliferative disorder

Primary CNS post-transplant lymphoproliferative disorder (PTLD) is a rare complication after solid organ transplantation, with the majority occurring in renal transplant recipients $(48,49)$. EBV infection is the major aetiologic factor in the development of PTLD-PCNSL (50). Twenty-eight cellular miRNAs exhibited differential expression in PTLD-PCNSL compared with systemic PTLD, including lower expression levels of miR-199a-5p/3p and miR-143/145 (implicated in NF- $\kappa B$ and c-Myc signalling) in the former (50). Moreover, EBV played a crucial effect on viral and cellular miRNA expression in PTLD-PCNSL. Several viral and cellular miRNA could distinguish non-EBV-associated
PTLD-PCNSL from EBV-associated PTLD-PCNSL. Moreover, a separate group of EBV-associated PTLDPCNSL that displayed reduced levels of B-cell lymphoma-associated oncogenic miRNAs (miR-155, miR21, miR-221 and miR-17-92 cluster) was identified (50).

\section{$m i R-28$ and BCL6}

A breakpoint in the BCL6 locus was observed in 38\% of the PCNSL evaluated. Among them, a deletion in $3 \mathrm{q}$ leads to loss of an $837 \mathrm{~kb}$ fragment of the lipoma-preferred partner $(L P P)$ gene. As miR-28 gene was located in LPP, the deletion may bring the BCL6 gene under the control miR-28 (51). BCL6 is commonly targeted by genetic aberrations and acts as an oncogene in germinal centre-derived lymphomas. BCL6 is known to prevent terminal B-cell differentiation largely through repression of PRDM1 (52).

\section{miRNAs as diagnostic markers for PCNSL}

miRNAs expression levels have been measured in the cerebrospinal fluid (CSF) from patients with PCNSL compared with other neurologic disorders using TaqMan quantitative real-time PCR assays. Among six candidate miRNAs (miR-15b, miR-19b, miR-21, miR-92a, miR106b, miR-204) detected, the levels of miR-21, miR-19b and miR-92a were significantly higher in the CSF of patients with PCNSL compared with those from control patients. The combination of these three miRNAs in CSF allowed for a stable diagnostic marker for PCNSL, with a diagnostic accuracy of $95.7 \%$ sensitivity and 96.7\% specificity (53). These data suggest that CSF miRNAs could be used as non-invasive diagnostic biomarkers for PCNSL. Importantly, these results were confirmed in an enlarged cohort $(n=39)$ of PCNSL patients with a sensitivity of $97.4 \%$. In addition, CSF levels of these miRNAs were significantly correlated with PCNSL status during treatment and/or disease follow-up (54), indicating their potential as biomarkers for treatment monitoring and follow-up. A recent meta-analysis also showed that, as compared with other CNS tumours, CSF-based miRNAs are more accurate and sensitive for diagnosing PCNSL (55).

Apart from measuring miRNA levels in CSF, Mao et al. reported that miR-21 levels in serum were significantly elevated in PCNSL as compared with normal controls in two independent cohorts with an area under the curve of 0.930 for the test cohort and 0.916 for the validation cohort. Raised serum levels of miR-21 could also differentiate PCNSL from major brain tumours, including glioblastoma (42). However, it is worthwhile to note that serum miR-21 has been identified as a 
diagnostic biomarker for other cancer types (56), including colorectal cancer (57), breast cancer (58) and hepatocellular carcinoma (59). These findings indicate that increased serum miR-21 levels are in general associated with malignancy and not specific for PCNSL. Another study demonstrated that higher serum levels of miR-222 could be a biomarker for early detection of DLBCL and PCNSL among HIV-infected individuals (60). It is propitious that, by combining CSF- and serum-based miRNAs with existing or emerging biomarkers, such as interleukin-10 (61) and U2 small nuclear RNA fragments (62) in CSF, the diagnostic sensitivity and accuracy of PCNSL will be enhanced.

\section{miRNAs as prognostic markers for PCNSL}

The current method for prognostication of PCNSL patients remains limited, in which only higher age and low Karnofsky Performance Status have consistently been shown to foreshadow a shorter overall survival (63). Therefore, devising novel prognostic tools for PCNSL could be an important step towards patientcentred therapy. In a recent study, Roth et al. profiled circulating miRNAs in PCNSL patients with short-term survival versus long-term survival where levels of 12 miRNAs were significantly different (64). Among these differentially abundant miRNAs, miR-151a-5p and miR$151 \mathrm{~b}$ demonstrated the most prominent alterations. Importantly, combined analysis of several miRNAs achieved a good separation between short- and longterm survivors with maximal area under curve of 0.75 . The prognostic significance of selected miRNAs was also validated in a second cohort by real-time PCR (64). In another study, the investigators demonstrated that serum miR-21 is an independent and powerful predictor of overall survival of PCNSL patients as analysed by Kaplan-Meier curve and multivariable Cox regression (42). In a study determining the treatment efficacy of pemetrexed (a folate anti-metabolite) plus rituximab (a CD20-targeting monoclonal antibody), the median time to progression (PFS) was significantly different in PCNSL patients with different serum levels of miR-21. Higher levels of serum miR-21 predicted a poor survival with PFS of 5.7 months compared with lower serum miR-21 with PFS of 9.0 months (65). In conclusion, circulating miRNAs might serve as prognostic biomarkers and treatment response predictors in PCNSL patients.

\section{Conclusions}

PCNSL is a rare malignant tumour with poor prognosis, accounting for approximately $3 \%$ of primary intracranial tumours. PCNS-DLBCL is the major subtype of
PCNSL. Our understanding of the cellular origin and pathogenic mechanisms of PCNSL remains fragmented. Pertinent to clinical practice, diagnosis of PCNSL is difficult owing to the lack of specific symptoms. miRNAs are small non-coding RNAs that function as master regulators in many physiological and pathological processes, particularly cancers. Recent studies have revealed the dysregulation of miRNAs in PCNSL using array-based miRNA profiling and real-time PCR. Nevertheless, study on the functional roles of these deregulated miRNAs in PCNSL is still limited. In addition, many reports have demonstrated the potential utilization of miRNAs as novel diagnostic and prognostic markers. Further investigations are warranted to maximize the clinical potentials of miRNA-based diagnostics and therapeutics in PCNSL.

\section{Acknowledgements}

This work was supported by grants from the National Natural Science Foundation of China (NSFC) (Grant number: 81401847).

\section{References}

1 Hoang-Xuan K, Bessell E, Bromberg J, Hottinger AF, Preusser M, Rudà R et al. (2015) Diagnosis and treatment of primary CNS lymphoma in immunocompetent patients: guidelines from the European Association for Neuro-Oncology. Lancet Oncol. 16, e322-e332.

2 Kleinschmidt-DeMasters BK, Damek DM, Lillehei KO, Dogan A, Giannini C (2008) Epstein Barr virus-associated primary CNS lymphomas in elderly patients on immunosuppressive medications. J. Neuropathol. Exp. Neurol. 67, 1103-1111.

3 Ivers LC, Kim AY, Sax PE (2004) Predictive value of polymerase chain reaction of cerebrospinal fluid for detection of Epstein-Barr virus to establish the diagnosis of HIV-related primary central nervous system lymphoma. Clin. Infect. Dis. 38, 1629-1632.

4 Ferreri AJ, Verona C, Politi LS, Chiara A, Perna L, Villa E et al. (2011) Consolidation radiotherapy in primary central nervous system lymphomas: impact on outcome of different fields and doses in patients in complete remission after upfront chemotherapy. Int. J. Radiat. Oncol. Biol. Phys. 80, 169-175.

5 Moise L, Matta C, Hanna C, Pilorge S, Ferme C, Durrbach A et al. (2011) Methotrexate- and/or cytarabine-based chemotherapy may be effective and safe in solid-organ transplant recipients with primary central nervous system lymphomas. Leuk. Lymphoma 52, 521-524.

6 Shi X, Zhang X, Yi C, Wang X, Chen Z, Zhang B et al. (2013) The combination of $13 \mathrm{~N}$-ammonia and $18 \mathrm{~F}-\mathrm{FDG}$ in predicting primary central nervous system lymphomas in immunocompetent patients. Clin. Nucl. Med. 38, 98-102.

7 Jezersek Novakovic B (2012) Treatment outcomes and survival in patients with primary central nervous system lymphomas treated between 1995 and 2010 - a single centre report. Radiol. Oncol. 46, 346-353.

8 Ferreri AJ, Reni M (2005) Prognostic factors in primary central nervous system lymphomas. Hematol. Oncol. Clin. North Am. 19, 629-649, vi. 
9 Richter J, Ammerpohl O, Martin-Subero JI, Montesinos-Rongen M, Bibikova M, Wickham-Garcia E et al. (2009) Array-based DNA methylation profiling of primary lymphomas of the central nervous system. BMC Cancer 9, 455.

10 Gonzalez-Aguilar A, Idbaih A, Boisselier B, Habbita N, Rossetto M, Laurenge A et al. (2012) Recurrent mutations of MYD88 and TBL1XR1 in primary central nervous system lymphomas. Clin. Cancer Res. 18, 5203-5211.

11 Lu SS, Kim SJ, Kim HS, Choi CG, Lim YM, Kim EJ et al. (2014) Utility of proton MR spectroscopy for differentiating typical and atypical primary central nervous system lymphomas from tumefactive demyelinating lesions. AJNR Am. J. Neuroradiol. 35, 270-277.

12 Montesinos-Rongen M, Siebert R, Deckert M (2009) Primary lymphoma of the central nervous system: just DLBCL or not? Blood 113, 7-10.

13 Louveau A, Smirnov I, Keyes TJ, Eccles JD, Rouhani SJ, Peske JD et al. (2015) Structural and functional features of central nervous system lymphatic vessels. Nature 523, 337-341.

14 Sung CO, Kim SC, Karnan S, Karube K, Shin HJ, Nam DH et al. (2011) Genomic profiling combined with gene expression profiling in primary central nervous system lymphoma. Blood 117, 12911300 .

15 Braggio E, Van Wier S, Ojha J, McPhail E, Asmann YW, Egan J et al. (2015) Genome-wide analysis uncovers novel recurrent alterations in primary central nervous system lymphomas. Clin. Cancer Res. 21, 3986-3994.

16 Chang C, Lin CH, Cheng AL, Medeiros LJ, Chang KC (2015) Primary central nervous system diffuse large B-cell lymphoma has poorer immune cell infiltration and prognosis than its peripheral counterpart. Histopathology 67, 625-635.

17 Pasqualucci L, Neumeister P, Goossens T, Nanjangud G, Chaganti RS, Küppers R et al.. (2001) Hypermutation of multiple protooncogenes in B-cell diffuse large-cell lymphomas. Nature $\mathbf{4 1 2}$, 341-346.

18 Li Z, Yu X, Shen J, Chan MT, Wu WK (2015) MicroRNA in intervertebral disc degeneration. Cell Prolif. 48, 278-283.

19 Li J, You T, Jing J (2014) MiR-125b inhibits cell biological progression of Ewing's sarcoma by suppressing the PI3K/Akt signalling pathway. Cell Prolif. 47, 152-160.

$20 \mathrm{Yu} \mathrm{X,} \mathrm{Li} \mathrm{Z,} \mathrm{Liu} \mathrm{J} \mathrm{(2015)} \mathrm{MiRNAs} \mathrm{in} \mathrm{primary} \mathrm{cutaneous} \mathrm{lym-}$ phomas. Cell Prolif. 48, 271-277.

21 Li Z, Yu X, Shen J, Law PT, Chan MT, Wu WK et al. (2015) MicroRNA expression and its implications for diagnosis and therapy of gallbladder cancer. Oncotarget 6, 13914-13924.

$22 \mathrm{Yu} \mathrm{X,} \mathrm{Li} \mathrm{Z} \mathrm{(2015)} \mathrm{The} \mathrm{role} \mathrm{of} \mathrm{MicroRNAs} \mathrm{expression} \mathrm{in} \mathrm{laryngeal}$ cancer. Oncotarget 6, 23297-23305.

23 Li Z, Yu X, Shen J, Jiang Y (2015) MicroRNA dysregulation in uveal melanoma: a new player enters the game. Oncotarget 6, $4562-4568$.

$24 \mathrm{Yu} \mathrm{X,} \mathrm{Li} \mathrm{Z} \mathrm{(2014)} \mathrm{MicroRNAs} \mathrm{regulate} \mathrm{vascular} \mathrm{smooth} \mathrm{muscle}$ cell functions in atherosclerosis (review). Int. J. Mol. Med. 34, 923-933.

25 Yu X, Li Z, Shen J, Wu WK, Liang J, Weng X et al. (2013) MicroRNA-10b promotes nucleus pulposus cell proliferation through RhoC-Akt pathway by targeting HOXD10 in intervetebral disc degeneration. PLOS ONE 8, e83080.

26 Li Z, Lei H, Luo M, Wang Y, Dong L, Ma Y et al. (2015) DNA methylation downregulated mir-10b acts as a tumor suppressor in gastric cancer. Gastric Cancer 18, 43-54.

27 Li Z, Yu X, Wang Y, Shen J, Wu WK, Liang J et al. (2015) By downregulating TIAM1 expression, microRNA-329 suppresses gastric cancer invasion and growth. Oncotarget 6, 17559-17569.
28 Li Z, Yu X, Shen J, Wu WK, Chan MT (2015) MicroRNA expression and its clinical implications in Ewing's sarcoma. Cell Prolif. 48, $1-6$.

29 Huang J, Zhang SY, Gao YM, Liu YF, Liu YB, Zhao ZG et al. (2014) MicroRNAs as oncogenes or tumour suppressors in oesophageal cancer: potential biomarkers and therapeutic targets. Cell Prolif. 47, 277-286.

30 Dong R, Liu X, Zhang Q, Jiang Z, Li Y, Wei Y et al. (2014) miR-145 inhibits tumor growth and metastasis by targeting metadherin in high-grade serous ovarian carcinoma. Oncotarget 5, 10816-10829.

31 Gougelet A, Perez J, Pissaloux D, Besse A, Duc A, Decouvelaere AV et al. (2011) miRNA Profiling: How to Bypass the Current Difficulties in the Diagnosis and Treatment of Sarcomas. Sarcoma 2011, 460650.

32 Song MY, Pan KF, Su HJ, Zhang L, Ma JL, Li JY et al. (2012) Identification of serum microRNAs as novel non-invasive biomarkers for early detection of gastric cancer. PLOS ONE 7, e33608.

33 Fischer L, Hummel M, Korfel A, Lenze D, Joehrens K, Thiel E. (2011) Differential micro-RNA expression in primary CNS and nodal diffuse large B-cell lymphomas. Neuro. Oncol. 13, 10901098.

34 Zheng J, Xu J, Ma S, Sun X, Geng M, Wang L (2013) Clinicopathological study of gene rearrangement and microRNA expression of primary central nervous system diffuse large B-cell lymphomas. Int. J. Clin. Exp. Pathol. 6, 2048-2055.

35 Robertus JL, Harms G, Blokzijl T, Booman M, de Jong D, van Imhoff G et al. (2009) Specific expression of miR-17-5p and miR127 in testicular and central nervous system diffuse large B-cell lymphoma. Mod. Pathol. 22, 547-555.

36 Yuan J, Chen L, Chen X, Sun W, Zhou X (2012) Identification of serum microRNA-21 as a biomarker for chemosensitivity and prognosis in human osteosarcoma. J. Int. Med. Res. 40, 2090-2097.

37 Chusorn P, Namwat N, Loilome W, Techasen A, Pairojkul C, Khuntikeo N et al. (2013) Overexpression of microRNA-21 regulating PDCD4 during tumorigenesis of liver fluke-associated cholangiocarcinoma contributes to tumor growth and metastasis. Tumour Biol. 34, 1579-1588.

38 Karakatsanis A, Papaconstantinou I, Gazouli M, Lyberopoulou A, Polymeneas G, Voros D et al. (2013) Expression of microRNAs, miR-21, miR-31, miR-122, miR-145, miR-146a, miR-200c, miR221, miR-222, and miR-223 in patients with hepatocellular carcinoma or intrahepatic cholangiocarcinoma and its prognostic significance. Mol. Carcinog. 52, 297-303.

39 Wang LJ, He CC, Sui X, Cai MJ, Zhou CY, Ma JL et al. (2015) MiR-21 promotes intrahepatic cholangiocarcinoma proliferation and growth in vitro and in vivo by targeting PTPN14 and PTEN. Oncotarget 6, 5932-5946.

40 Go H, Jang JY, Kim PJ, Kim YG, Nam SJ, Paik JH et al. (2015) MicroRNA-21 plays an oncogenic role by targeting FOXO1 and activating the PI3K/AKT pathway in diffuse large B-cell lymphoma. Oncotarget 6, 15035-15049.

41 Gu L, Song G, Chen L, Nie Z, He B, Pan Y et al. (2013) Inhibition of miR-21 induces biological and behavioral alterations in diffuse large B-cell lymphoma. Acta Haematol. 130, 87-94.

42 Mao X, Sun Y, Tang J (2014) Serum miR-21 is a diagnostic and prognostic marker of primary central nervous system lymphoma. Neurol. Sci. 35, 233-238.

43 Tanaka Y, Kamohara H, Kinoshita K, Kurashige J, Ishimoto T, Iwatsuki M et al. (2013) Clinical impact of serum exosomal microRNA-21 as a clinical biomarker in human esophageal squamous cell carcinoma. Cancer 119, 1159-1167. 
44 Zanussi S, Bortolin MT, Pratesi C, Tedeschi R, Basaglia G, Abbruzzese L et al. (2015) Autograft HIV-DNA load predicts HIV-1 peripheral reservoir after stem cell transplantation for AIDSrelated lymphoma patients. AIDS Res. Hum. Retroviruses 31, 150159.

45 Epeldegui M, Vendrame E, Martinez-Maza O (2010) HIV-associated immune dysfunction and viral infection: role in the pathogenesis of AIDS-related lymphoma. Immunol. Res. 48, 72-83.

46 Thapa DR, Li X, Jamieson BD, Martinez-Maza O (2011) Overexpression of microRNAs from the miR-17-92 paralog clusters in AIDS-related non-Hodgkin's lymphomas. PLOS ONE 6, e20781.

47 Olive V, Bennett MJ, Walker JC, Ma C, Jiang I, Cordon-Cardo C et al. (2009) miR-19 is a key oncogenic component of mir-17-92. Genes Dev. 23, 2839-2849.

48 Cavadas PC, Thione A, Blanes M, Mayordomo-Aranda E (2015) Primary Central Nervous System Posttransplant Lymphoproliferative Disease in a Bilateral Transfemoral Lower Extremity Transplantation Recipient. Am. J. Transplant. 15, 2758-2761.

49 Kempf C, Tinguely M, Rushing EJ (2013) Posttransplant lymphoproliferative disorder of the central nervous system. Pathobiology 80, 310-318.

50 Fink SE, Gandhi MK, Nourse JP, Keane C, Jones K, Crooks P et al. (2014) A comprehensive analysis of the cellular and EBVspecific microRNAome in primary CNS PTLD identifies different patterns among EBV-associated tumors. Am. J. Transplant. 14, 2577-2587.

51 Schwindt H, Akasaka T, Zuhlke-Jenisch R, Hans V, Schaller C, Klapper W et al. (2006) Chromosomal translocations fusing the BCL6 gene to different partner loci are recurrent in primary central nervous system lymphoma and may be associated with aberrant somatic hypermutation or defective class switch recombination. $J$. Neuropathol. Exp. Neurol. 65, 776-782.

52 Wagner SD, Ahearne M, Ko Ferrigno P (2011) The role of BCL6 in lymphomas and routes to therapy. Br. J. Haematol. 152, 3-12.

53 Baraniskin A, Kuhnhenn J, Schlegel U, Chan A, Deckert M, Gold $\mathrm{R}$ et al. (2011) Identification of microRNAs in the cerebrospinal fluid as marker for primary diffuse large B-cell lymphoma of the central nervous system. Blood 117, 3140-3146.

54 Baraniskin A, Kuhnhenn J, Schlegel U, Schmiegel W, Hahn S, Schroers R et al. (2012) MicroRNAs in cerebrospinal fluid as biomarker for disease course monitoring in primary central nervous system lymphoma. J. Neurooncol. 109, 239-244.
55 Wei D, Wan Q, Li L, Jin H, Liu Y, Wang Y et al. (2015) MicroRNAs as potential biomarkers for diagnosing cancers of central nervous system: a meta-analysis. Mol. Neurobiol. 51, 1452-1461.

56 Wang Y, Gao X, Wei F, Zhang X, Yu J, Zhao H et al. (2014) Diagnostic and prognostic value of circulating miR-21 for cancer: a systematic review and meta-analysis. Gene 533, 389-397.

57 Toiyama Y, Takahashi M, Hur K, Nagasaka T, Tanaka K, Inoue Y et al. (2013) Serum miR-21 as a diagnostic and prognostic biomarker in colorectal cancer. J. Natl Cancer Inst. 105, 849-859.

58 Gao J, Zhang Q, Xu J, Guo L, Li X (2013) Clinical significance of serum miR-21 in breast cancer compared with CA153 and CEA. Chin. J. Cancer Res. 25, 743-748.

59 Xu J, Wu C, Che X, Wang L, Yu D, Zhang T et al. (2011) Circulating microRNAs, miR-21, miR-122, and miR-223, in patients with hepatocellular carcinoma or chronic hepatitis. Mol. Carcinog. 50, 136-142.

60 Thapa DR, Hussain SK, Tran WC, D'Souza G, Bream JH, Achenback CJ et al. (2014) Serum microRNAs in HIV-infected individuals as pre-diagnosis biomarkers for AIDS-NHL. J. Acquir. Immune Defic. Syndr. 66, 229-237.

61 Sasayama T, Nakamizo S, Nishihara M, Kawamura A, Tanaka H, Mizukawa K et al. (2012) Cerebrospinal fluid interleukin-10 is a potentially useful biomarker in immunocompetent primary central nervous system lymphoma (PCNSL). Neuro. Oncol. 14, 368-380.

62 Baraniskin A, Zaslavska E, Nopel-Dunnebacke S, Ahle G, Seidel S, Schlegel U et al. (2016) Circulating U2 small nuclear RNA fragments as a novel diagnostic biomarker for primary central nervous system lymphoma. Neuro. Oncol. 18, 361-367.

63 Abrey LE, Ben-Porat L, Panageas KS, Yahalom J, Berkey B, Curran W et al. (2006) Primary central nervous system lymphoma: the Memorial Sloan-Kettering Cancer Center prognostic model. J. Clin. Oncol. 24, 5711-5715.

64 Roth P, Keller A, Hoheisel JD, Codo P, Bauer AS, Backes C et al. (2015) Differentially regulated miRNAs as prognostic biomarkers in the blood of primary CNS lymphoma patients. Eur. J. Cancer 51, 382-390.

65 Zhao HT, Chen J, Shi SB, Tian J, Tao RJ (2015) Pemetrexed plus rituximab as second-line treatment for primary central nervous system lymphoma. Med. Oncol. 32, 351. 